\title{
A Prospective Study on Role of Water Soluble Contrast in Management of Small Bowel Obstruction
}

\author{
Kundan", Ravindra Kumar, Amarnath Kumar, Pawanjeet Kumar \\ Department of Surgery, Patna Medical College, Patna, India
}

Email address:

kundansingh1987@gmail.com (Kundan)

${ }^{*}$ Corresponding author

\section{To cite this article:}

Kundan, Ravindra Kumar, Amarnath Kumar, Pawanjeet Kumar. A Prospective Study on Role of Water Soluble Contrast in Management of Small Bowel Obstruction. Journal of Surgery. Vol. 4, No. 3, 2016, pp. 71-75. doi: 10.11648/j.js.20160403.12

Received: June 12, 2016; Accepted: June 20, 2016; Published: July 4, 2016

\begin{abstract}
There is no definite protocol in management of small bowel obstruction in relation to duration and need of surgery. The aim is to study the role of gastrografin in management of small bowel obstruction. In this study patients who were diagnosed with intestinal obstruction were administered gastrografin. The patients were followed serially using x-ray at $4 \mathrm{hrs}$ interval for $24 \mathrm{hrs}$; decision to operate was taken on non-progression of dye in two consecutive x-ray. Among 20 patients of this study 9 patients were operated on basis of gastrografin study. 11 were treated conservatively. 8 patients were of adhesive bowel obstruction. Out of which 1 was operated, 7 were treated conservatively. The sensitivity, specificity, positive and negative predictive value of gastrografin administration in this study was $100 \%, 89 \%, 92 \%, 100 \%$ respectively. Gastrografin helps in strengthening the clinical decision about the management of intestinal obstruction; it helps in early decision making regarding continuing the conservative or operative management and allows the introduction of oral intake earlier and earlier discharge from the hospital as well as reduction in operative rate.
\end{abstract}

Keywords: Gastrografin, Adhesive Bowel Obstruction, Sensitivity, Specificity, Positive and Negative, Predictive Value

\section{Introduction}

Intestinal obstruction is the most common abdominal emergency and cause of frequent admissions at surgical emergency wards. The most effective way to reduce the morbidity and mortality caused by intestinal obstruction is therefore, through the early diagnosis and the appropriate treatment. The improved tool for early diagnosis and treatment has reduced the mortality due to it to 5 to $10 \%$ [1].

Serial x-ray monitoring of the gastrografin ${ }^{\circledR}$ transit has been found to be more sensitive and specific in predicting wither the obstruction is partial or there is complete obstruction $[2,3,4]$.

Considering the above facts, this study was designed to assess the value of water soluble contrast radiography as a diagnostic tool and its ability to aid surgical decision in patients with intestinal obstruction at Patna medical college and hospital. This study is a prospective study which was conducted at patna medical college and hospital, in the Emergency ward, Department of surgery; in which patients were divided into two group; one group was managed on classical conservative line of management, and the other group was given oral water soluble contrast gastrograffin ${ }^{\circledR}$ at the time of admission and serial x-ray of abdomen were taken and decision whether to operate or continue the conservative was based on progression was dye in the x-ray. Results of the study were noted and analyzed. The primary end point of the study was need of surgery and duration of stay in the hospital.

\section{Methods}

This study was carried out at Patna medical college \& hospital in the department of surgery from 2014 to 2015 in 20 patients. The patients who presented to surgical emergency at our hospital were selected for this study keeping in mind the exclusion criteria of this study.

Following were the inclusion criteria for the patients in the study:
1. Any age
2. Any sex
3. Presenting complaints: 
Abdominal pain,

Distension,

Vomiting,

Not able to pass stool \& flatus

1. Hemodynamically stable

2. Radiological evidence of intestinal obstruction (multiple gas fluid level in X-ray)

3. Sonological evidence of intestinalobstruction (dilated bowelloop in ultra-sonogram)

4. The patients giving informed and written consent to be included in the study group.

Following were the exclusion criteria:

1. toxemia

2. Hemodynamically unstable

3. Features of peritonitis

4. History of any trauma to the abdomen

5. History of intra-abdominal malignancy

6. History suggestive of inflammatory bowel disease

7. History of surgery within 30 days

8. Known history of asthma

9. Known history of allergy to iodine / contrast agent

10. History of abdominal irradiation

Patients were put on intravenous infusions, with complete rest to the bowel and nil by mouth. Ryle's tube was inserted through nasal cavity and frequent aspirations were done. Blood investigations were sent. X-ray erect abdomen was taken. Ultrasonography of whole abdomen was done. The monitoring of input as well as output, along with frequent recording of all the vital signs was done. It was made sure the patients are well hydrated and all the gastric contents has been aspirated before gastrograffin $^{\circledR}$ being administered to avoid dehydration and aspiration by the patients. After that $100 \mathrm{ml}$ of water soluble oral contrast Gastrograffin (10 g sodium amidotrizoate and 66 $\mathrm{g}$ meglumine amidotrizoate) for adults and $60 \mathrm{ml}$ for pediatric patients was given through ryles tube and serial $\mathrm{x}$ rays erect abdomen Anterio-posterior view were taken at the interval of 4 hrs $(0,4,8,12,16,24)$ and the progression of gastrograffin ${ }^{\circledR}$ was noted. If there was no progression of dye in two consecutive contrast $\mathrm{x}$-rays, then the patient was considered for surgery and the operative findings were noted.

In the patients in whom the contrast appeared in the rectal region within the $24 \mathrm{hrs} \mathrm{x}$-ray monitoring was considered for continuation of conservative and was considered to have partial obstruction.

The data were collected in the terms of:

1. Age

2. Sex

3. Presenting complaints

4. Duration of presenting complaints

5. Previous history of surgery

6. Time Duration since last surgery

7. Type of previous surgery

8. Whether considered for surgery or conservative

9. Time duration of delay in considering for surgery

10. Type of operation done

11. Duration of stay in the hospital in conservative patients

12. Duration of stay in operated patients
13. Whether patient expired or discharged

The statistical analysis of the data obtained were done by SPSS statistics 17.0 ver. (IBM Chicago, IL, USA). The test performed were Chi-squar test, Fishser-excat test Unpaired test, Mann Whiteny test. P Value of the entire study was kept as $<0.050$.

The result obtained from this study was compared with the similar studies in the past and their outcomes were discussed.

\section{Results}

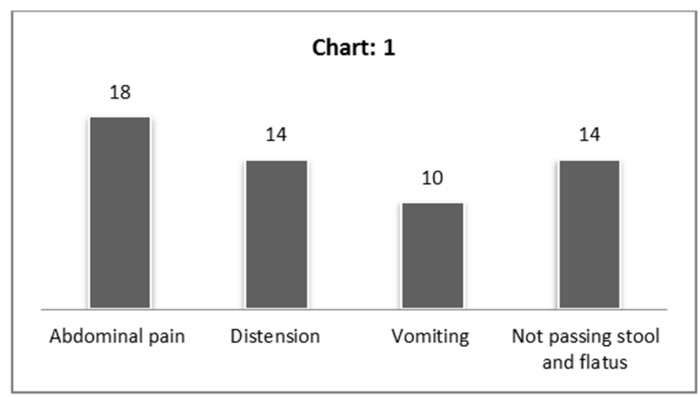

Figure 1. Frequency of presenting complaints.

From April 2014 to October 2015, 20 patients of intestinal obstruction were included in this study after satisfying the exclusion and inclusion criteria at Emergency ward Department of general surgery, Patna Medical College, Patna. There were 12 males and 8 female with male: female ratio as $1.5: 1$ (table: 1 ). The mean age in this study was 39.5 yrs (range 5 months -80 years). The mean duration of presenting complaints was 4 days (range 1 -8 days).

All the cardinal features were present in varying proportions in the patients (Figure: 1). Abdominal pain was the most common presenting complaints in $90 \%$ of the patients followed by absolute constipation in $70 \%$ of the patients. Abdominal distension was present in $70 \%$ of the patients and vomiting in $50 \%$ of the patients. 8 patients $(40 \%)$ had a previous history of surgery. Out of which $5 \%$ of the patients had history of more than 1 surgery.

Gynecological surgeries (50\%) followed by emergency exploratory laparotomy (37.5\%) and appendectomy (12.5\%) was most common previous surgeries (Figure: 2). The mean time gap between antecedent abdominal surgery and the episode of intestinal obstruction was 9.5 months.

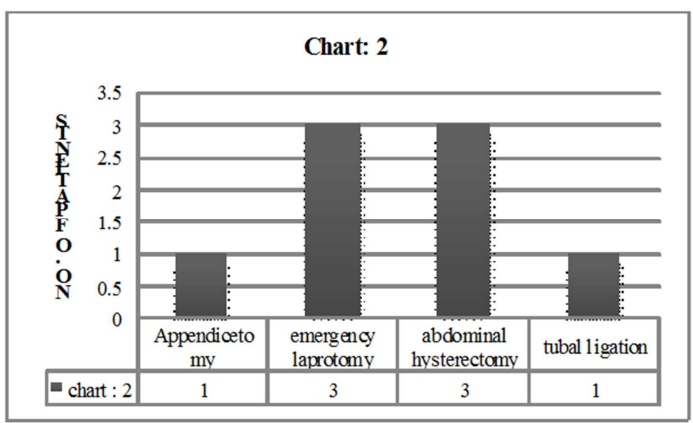

Figure 2. Previous surgeries done on patients. 
11 patients (55\%) were treated successfully on conservative treatment while 9 patients $(45 \%)$ were operated (table: 1). Resection and anastomosis was most common surgery followed by Adhesolysis, ileostomy (Figure: 3). Among the total 8 patients with post-operative adhesions one was operated and 7 were treated conservatively.

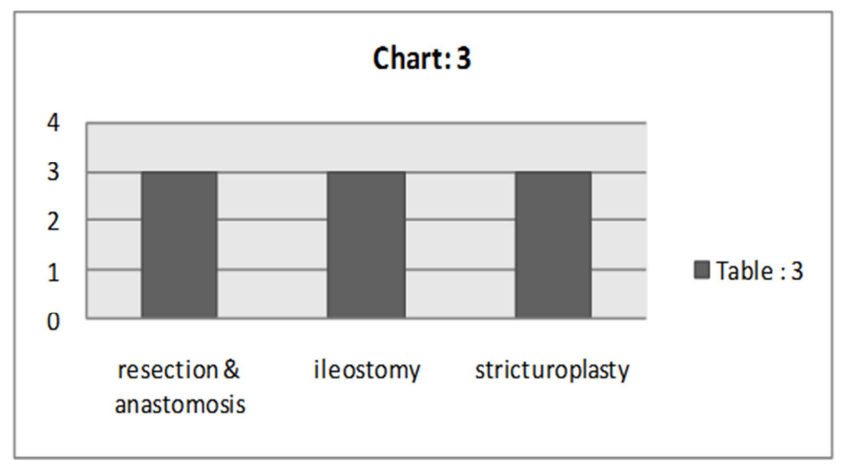

Figure 3. Types of surgeries.

In this study the mean duration of time gap between admission and decision to operate was $13.56 \mathrm{hrs}$ (range $8 \mathrm{hrs}-$ 2 days) (table: 1). Mean duration of stay in the conservative subset was 4.18 days. The mean duration of stay in the operative subset was 11.56 days. 19 patients were discharged successfully while one patient expired. The sensitivity, specificity, positive predictive value, negative predictive value of gastrografin administration in this study was $100 \%$, $90 \%, 91 \%, 100 \%$ respectively (table: 2 ).

Table 1. Results of this study.

\begin{tabular}{ll}
\hline Total no. pts & $\mathbf{2 0}$ \\
\hline Male & 12 \\
Female & 8 \\
Mean Age & $39.57 \mathrm{yrs}$ \\
Mean duration of presenting complaints & 4 days \\
H/o surgery & $8(40 \%)$ \\
Mean duration till conservative continued & $13.56 \mathrm{hrs}$ \\
No. of pts on conservative & $11(55 \%)$ \\
No. of pts operated & $9(45 \%)$ \\
\hline
\end{tabular}

\section{Discussion}

Intestinal obstruction is an important cause of admission in the department of general surgery, Emergency ward in most of the hospitals in the world. Early diagnosis and treatment helps in reducing the morbidity and mortality among the patients of intestinal obstruction. There is no defined protocol regarding the management of intestinal obstruction, no definite duration till which the conservative management can be continued. Accurate diagnosis can prevent unnecessary operation, thereby reducing the morbidity and mortality. The delay in decision to operate may increase the chances of resections and stoma formation.

Many prospective studies have been conducted similar to this study. Stordahl [5] et al on 50 patient, Joyce WP et al [6] on 127 patients, Assalia et al [7] on 99 patients, chung et al
[8] on 51 patients, Feigin et al [9] on 50 patients, chen et al [10] on 161 patients, chen et al [11] again on 116 patients, Fevang et al [12] on 35 patients, Hkchoi et al [13] on 124 patients, again HK choi et al [14] in on 212 patients, Biondo et al [15] on 92 patients conducted a similar study worldwide.

In India kapoor et al [16] on 24 patients, vakilrakesh et al [17] on 32 patients, skgupta et al [18] on 20 patients, Rkgupta et al [19] on 58 patients did similar study.

In this study Gastografin ${ }^{(B} 100 \mathrm{ml}(100 \mathrm{ml}$ contain $10 \mathrm{~g}$ Sodium diatriazoate \& $66 \mathrm{~g}$ Meglumine Amidotriazoate) has been used as oral water soluble contrast agent in adults and gastrograffin $60 \mathrm{ml}$ has been used in pediatric patients more than 6 yrs of age and gastrografin $30 \mathrm{ml}$ has been used in patient less than 6 years of age. Stordah et al [5] in did a double blinded RCT on comparison of hyper-osmolar contrast agent Gastrograffin and Omnipaque. Chung et al [8] in had used $76 \%$ urograffin for their study. Joyce wp et al [6], Assalia [7] Fevang [12], Choi [13], Biondo et al [15], Burge et al [20], kapoor et al [16] has used gastrografin $100 \mathrm{ml}$ in their study. Feigin et al [21] in 1996 has used Meglumine ioxitalamate $(100 \mathrm{ml})$ in their study. Chen et al $[10,11]$ has used $40 \mathrm{ml}$ urografin mixed with $40 \mathrm{ml}$ of water in their study.

The male: female ratio was 1.5: 1 in this study. The degree of slight male predominance is consistence with previous studies. Sarraf [22] et al in 1983 had reported a ratio of 1.14:1. Among Indian studies Skgupta et al [18] in his study had male: female ratio of 1.2:1. In the present study gynecological surgery (35\%) followed by emergency laprotomy (25\%), Appendectomy (20\%) was the most common surgeries preceding the episodes of intestinal obstruction. Studies have reported gynecological and colorectal surgeries and appendicectomy as most common procedure causing the postoperative intestinal obstruction. Abdallah ME et al [23] has reported gynecological surgery $(28 \%)$ as the most common cause, Casper haule et al [24] has reported previous surgery for intestinal obstruction (42\%) as the most common cause. Among Indian studies vakilrakesh et al [17] has described appendectomy (34\%) as the commonest preceding surgery. RK gupta et al [19] has described appendicetomy $(31 \%)$ as the most common antecedent surgery following the episode of intestinal obstruction. The success rate of conservative treatment was $40 \%$ in the present study. The success rate of conservative treatment for intestinal has been described as being between $73 \%$ and $90 \%$ [25]. Rakeshgupta et al. [19] has reported this rate to be $75.8 \%$ in their study.

The duration of conservative treatment in patients with intestinal obstruction remains controversial. Seror et al. [25] reported that this period could be prolonged up to 5 days in patients with intestinal obstruction caused by post-operative adhesions, whereas Sosa and Gardner [26] considered that conservative treatment could be performed for only $24-48$ $\mathrm{h}$, unless there were signs of strangulation. Assalia et al. [7] recommended $48 \mathrm{~h}$, Bizer et al. [27] $24 \mathrm{~h}$ and Brolin et al [28] $48-72 \mathrm{~h}$. Hofstetter [29] suggested that surgical 
treatment should be undertaken in obstruction not relieved within $24 \mathrm{~h}$ and others have reported that conservative treatment should be limited to $12,24,48$ or $72 \mathrm{~h}$. In this study the mean duration till which the conservative was continued before being decided to be operated was $13.56 \mathrm{hrs}$.

In this study the mean duration of Hospital stay of the patients in conservative subset was 4.18 days. The mean duration of hospital stay of the patients in the operated subset was 11.6 days (range 10-13 days). In the study by Salomone et al [30] (GUSBOCA TRIAL) the mean difference of hospital stay in subset of patient who did not required surgery in the gastrografin group was 3 days compared to 5 days in the control group for the same subset of patients, While the mean duration of stay in subset of patient who were operated in the gastrografin group was 4.7 days compared to 7.8 days in the similar subset of patient in the test group Casper haule et al [24] in their study reported duration of say in the hospital in the gastrografin group was 5.62 day compared to 10.88 days in the conservative group.

In present study the sensitivity, specificity, positive predictive value, negative predictive value of gastrografin administration was $100 \%, 89 \%, 92 \%, 100 \%$ respectively (table: 2 ).

Table 2. Comparisons of sensitivity, specificity, positive predictive value \& negative predictive value.

\begin{tabular}{lllll}
\hline & Sensitivity & Specificity & $\begin{array}{l}\text { Positive } \\
\text { predictive } \\
\text { value }\end{array}$ & $\begin{array}{l}\text { Negative } \\
\text { predictive } \\
\text { value }\end{array}$ \\
\hline Joyce WP [6] & 98 & 100 & 100 & 85 \\
Chung [8] & 92 & 91 & 96 & 83 \\
Chen [11] & 98 & 100 & 100 & 96 \\
Biondo [15] & 100 & 100 & 100 & 100 \\
Rkgupta [19] & 88.6 & 100 & 100 & 73.6 \\
Skgupta [18] & 72 & 100 & 100 & 75 \\
Present study & 100 & 89 & 92 & 100 \\
\hline
\end{tabular}

\section{Conclusion}

Gastrografin helps in strengthening the clinical decision about the management of intestinal obstruction; it helps in early decision making regarding continuing the conservative or operative management and allows the introduction of oral intake earlier and earlier discharge from the hospital as well as reduction in operative rate.

\section{References}

[1] McEntee G, Pender D, Mulvin D, McCullough M, Naeeder S, Farah S, et al. Current spectrum of intestinal obstruction. Br J Surg 1987; 74: 976-980.

[2] Anderson CA, Humphrey WT. Contrast radiography in small bowel obstruction: a prospective randomized trial. Mil Med 1997; 162: 749-52.

[3] Duron J. J, Jourdan-Da Silva N, Montcel S. T., Berger A, Muscari F, Hennet H, Veyrieres M, Hay JM. Adhesive Postoperative Small Bowel Obstruction: Incidence and Risk
Factors of Recurrence After Surgical Treatment. Ann Surg. Nov 2006; 244 (5): 750-757.

[4] Owen H. Wangensteen. Historical aspect of the management of the acute intestinal obstruction. Surgery 1969; 63: 363-383.

[5] Stordahl A, Laerum F, Gjolberg T, Enge I (1988) Watersoluble contrast media in radiography of small bowel obstruction. Comparison of ionic and non-ionic contrast media. Acta Radiol 29: 53-56.

[6] Joyce WP, Delaney PV, Gorey TF, Fitzpatrick JM (1992) Thevalue of water-soluble contrast radiology in the management of acute small bowel obstruction. Ann R CollSurg Engl 74: 422-425.

[7] Assalia A, Schein M, Kopleman D, Hirshberg A, Hashmonai M. Therapeutic effect of oral Gastrographin in adhesive, partial small bowel obstruction: a prospective randomized trial. Surgery 1994; 115: 433-437.

[8] Chung CC, Meng WC, Yu SC, Leung KL, Lau WY, Li AK: A prospective study on the use of water-soluble contrast followthrough radiology in the management of small bowel obstruction: Aust N Z J Surg. 1996 Sep; 66 (9): 598-601

[9] Feigin E, Seror D, Szold A, Carmon M, Allweis TM, Nissan A, et al. Water-soluble contrast material has no therapeutic effect on postoperative small-bowel obstruction: results of a prospective, randomized clinical trial. Am J Surg 1996; 171: 227-229.

[10] Chen SC, Lin FY, Lee PH, Yu SC, Wang SM, Chang KJ (1998) Water-soluble contrast study predicts the need for early surgery in adhesive small bowel obstruction. Br J Surg 85: 1692-1694.

[11] Chen SC, Chang KJ, Lee PH, Wang SM, Chen KM, Lin FY. Oral urografin in postoperative small bowel obstruction. World J Surg 1999; 23: 1051-1054.

[12] Fevang BT, Fevang J, Stangeland L, Soreide O, Svanes K, Viste A. Complications and death after surgical treatment of small bowel obstruction: A 35-year institutional experience. Ann Surg 2000; 231: 529-537

[13] Choi HK, Chu KW, Law WL. Therapeutic value of Gastrografin in adhesive small bowel obstruction after unsuccessful conservative treatment: a prospective randomized trial. Ann Surg 2002; 236: 1-6.

[14] Hok-Kwok Choi, Wai-Lun Law, Judy Wai-Chu Ho, Kin-Wah Chu: Value of gastrografin in adhesive small bowel obstruction after unsuccessful conservative treatment: A prospective evaluation: World J Gastroenterol 2005; 11 (24): 3742-3745.

[15] Biondo S, Pares D, Mora L, Marti Rague J, Kreisler E, Jaurrieta E (2003) Randomized clinical study of Gastrografin administration in patients with adhesive small bowel obstruction. Br J Surg 90: 542-546.

[16] Kapoor S, Jain G, Sewkani A, Sharma S, Patel K, Varshney S (2006) Prospective evaluation of oral Gastrografin in postoperative small bowel obstruction. J Surg Res 131: 256260.

[17] Vakil rakesh sanjay kalra subrat raul yoel paljor sudhir joseph: role of water soluble contrast in management of adhesive small bowel obstruction: a randomized controlled study: Indian js 2007; 69: 47-51. 
[18] Sanjay K. Gupta: International Journal of Medical Science and Education Vol. 1; Issue: 3; July-Sept 2014.

[19] Rakesh Kumar Gupta, Chandra Sekhar Agrawal, Om Prakash Pathania, Rohit Prasad Yadav, Panna Lal Shah: A Prospective Study on the Gastrografin Contrast Radiology in the Management of Small Bowel Obstruction: Arch ClinExpSurg 2013; 2: 24-31.

[20] Burge J, Abbas SM, Roadley G, Donald J, Connolly A, Bissett IP, Hill AG (2005) Randomized controlled trial of Gastrografin in adhesive small bowel obstruction. ANZ J Surg 75: $672-67$.

[21] Feigin E, Seror D, Szold A, Carmon M, Allweis TM, Nissan A, et al. Water-soluble contrast material has no therapeutic effect on postoperative small-bowel obstruction: results of a prospective, randomized clinical trial. Am J Surg 1996; 171: 227-229.

[22] Sarraf-Yazdi S, Shapiro ML. Small bowel obstruction: the eternal dilemma of when to intervene. Scand J Surg 2010; 99: 78-80. Brolin RE. Partial small bowel obstruction. Surgery 1984; 95: 145-149.

[23] Abdallah ME (2010) Description of clinical presentation and management of patients presenting with postsurgical adhesion admitted at Mulago Hospital. MMED (Surgery) dissertation, Makerere University, Kampala.
[24] Caspar Haule, Peter A Ongom and Timothy Kimuli: Efficacy of Gastrografin Compared with Standard Conservative Treatment in Management of Adhesive Small Bowel Obstruction at Mulago National Referral Hospital: J Clin Trials 2013, 3: 4.

[25] Seror D, Feigin E, Szold A, et al. How conservative can postoperative small bowel obstruction be treated? Am J Surg 1993; 165: 121-126.

[26] Sosa J, Gardner B. Management of patients diagnosed as acute intestinal obstruction secondary to adhesions. Am Surg 1993; 59: 125-128.

[27] Bizer LS, Liebling RW, Delany HM, Gliedman ML. Small bowel obstruction: the role of nonoperative treatment in simple intestinal obstruction and predictive criteria for strangulation obstruction. Surgery 1981; 89: 407-413.

[28] Brolin RE, Krasna MJ, Mast BA. Use of tubes and radiographs in the management of small bowel obstruction. Ann Surg 1987; 206: 126-133.

[29] Hofstetter SR. Acute adhesive obstruction of the small intestine. SurgGynecolObstet 1981; 152: 141-144.

[30] Salomone Di SaverioÆ Fausto Catena $Æ$ Luca AnsaloniÆ Margherita GavioliÆ Massimo Valentino $Æ$ Antonio Daniele Pinna: World J Surg (2008) 32: 2293-2304, DOI 10.1007/s00268-008-9694-6. 